Journal of Applied Pharmaceutical Science Vol. 5 (09), pp. 016-020, September, 2015

Available online at http://www.japsonline.com

DOI: $10.7324 /$ JAPS.2015.50903

ISSN 2231-3354 (cc) BY-NC-SA

\title{
Evaluation of antimicrobial activities of Bacillus megaterium with a third-generation cephalosporin (ceftriaxone)
}

\author{
Tu HK Nguyen*, Le B Thu \\ School of Biotechnology, Hochiminh City International University, National University, Hochiminh city, Vietnam.
}

\begin{tabular}{|c|c|}
\hline ARTICLE INFO & ABSTRACT \\
\hline Article history: & \multirow{9}{*}{$\begin{array}{l}\text { Bacillus megaterium T04 isolated from Rach Lang stream in Vietnam was tested for antimicrobial activities. The } \\
\text { antimicrobial activities of Bacillus megaterium T04 }\left(57.3 \times 10^{8} \text { cfu/mL) against Candida albicans, Salmonella }\right. \\
\text { typhi, Pseudomonas aeruginosa, Staphylococcus sciuri, Micrococcus luteus were detected by agar well diffusion } \\
\text { method in different cultivation conditions at three temperatures }(25,37 \text {, and } 45 \mathrm{oC}) \text { in three incubation periods } \\
(24,48 \text {, and } 72 \text { hours). The efficacy of antimicrobial activities of this strain were determined in comparison with } \\
\text { ceftriaxone activity against Candida albicans, Salmonella typhi, Pseudomonas aeruginosa, Staphylococcus } \\
\text { scuiri, Micrococcus luteus. The antimicrobial activity potency was equivalent to ceftriaxone in a range }(3.30 .6 \\
\mu \mathrm{g} / \mathrm{mL} \text { to } 46.56 .2 \mu \mathrm{g} / \mathrm{mL}) \text { for Candida albicans }(0.90 .2 \mu \mathrm{g} / \mathrm{mL} \text { to } 35.57 .7 \mu \mathrm{g} / \mathrm{mL}) \text { for Salmonella typhi, },(0.4 \\
0.1 \mu \mathrm{g} / \mathrm{mL} \text { to } 28.44 .4 \mu \mathrm{g} / \mathrm{mL}) \text { for Pseudomonas aeruginosa, }(119.821 .2 \mu \mathrm{g} / \mathrm{mL} \text { to } 283.726 .0 \mu \mathrm{g} / \mathrm{mL}) \text { for } \\
\text { Staphylococcus scuiri, }(3.30 .4 \mu \mathrm{g} / \mathrm{mL} \text { to } 64.47 .4 \mu \mathrm{g} / \mathrm{mL}) \text { for Micrococcus luteus. }\end{array}$} \\
\hline Received on: $03 / 08 / 2015$ & \\
\hline Revised on: 28/08/2015 & \\
\hline Accepted on: 17/09/2015 & \\
\hline Available online: $27 / 09 / 2015$ & \\
\hline Key words: & \\
\hline antimicrobial activities, & \\
\hline Bacillus megaterium T04, & \\
\hline ceftriaxone, potency & \\
\hline
\end{tabular}

\section{INTRODUCTION}

Antibiotics have been the main therapy to combat these infections. However, the antibiotic resistance is rapidly increasing because of the messy drug usage. Therefore, it is very urgent to find out alternative antimicrobial therapies against these infections. Commonly, microorganisms living in soil produced antimicrobial agents. Remarkably, B. megaterium is found in diverse environments from food, seawater, sediments and even in bee honey (Vary, 1994). This strain produces high capacity for the production of exoenzymes. Hence, it is a potential industrial strain for more than 50 years. Some of enzymes and products have been used in industrial applications such as penicillin amidase used for generation of new synthetic antibiotics, amylases (Vihinen and Mantsala, 1989), neutral protease, steroid hydrolases, pyruvate and vitamin B12 (Vary, 1992; 2007). Bacillus megaterium has also been found to produce thermostable lipase during submerged fermentation (Anurag et al., 2006), antifungi, and antivirus like HIV, Hepatitis B virus, Herpes simplex corneal ulcers (Morita et al., 1999; Shimada et al., 1986; Shiota et al., 1996; Tseng et al., 1991).

\footnotetext{
* Corresponding Author

Email: nhktu@hcmiu.edu.vn
}

Recently, B. megaterium also could be considered for biopolymer production on an industrial scale because the possibility that the strain produced and accumulated a large content of PHB (Poly-3-hydroxybutyrate) (Rodriguez, 2013). This bacterium has also the ability to decolorize and biodegrade different azo dyes. Therefore, Bacillus megterium can be used for the treatment textile industry effluents containing various azo dyes (Maulin, 2014). B. megaterium is also found in unusual and sometimes toxic environments and may have potential as a toxic waste cleanup, as it is able to degrade persistent insecticides and ultilize them as carbon sources (Saxena et al., 1987; Selvanayagam and Vijaya, 1989). Bacillus megaterium and other members of the genus Bacillus are known to produce a wide antimicrobial agents. Bacillus megaterium produces bacteriocin, called as megacin, which is a highly specific antimicrobial protein against broader spectra of gram-negative bacteria, yeasts, fungi and gram-positive species as well (Abriouel et al., 2011) (Holland and Roberts, 1964). Some current bacteriocins are produced by Bacillus megaterium, which used on the market, including Megacin C (Donoghue, 1972), Megacin Cx (Brusilow \& Nelson, 1981), Megacin 19 (Khalil et al., 2009b) and Megacin 22 (Khalil et al., 2009a). Ceftriaxone is a third-generation cephalosporin which has excellent activity against many gram-negative, and most grampositive 1microorganisms. 
Ceftriaxone is used in treating bacterial meningitis; respiratory tract, urinary tract, soft tissue, bone and joint infections; and gonorrhea. Ceftriaxone has been well tolerated except for diarrhea, which in most cases has not required a change in therapy. Patients who commonly had cross - hypersensitivity will be not prescribed ceftriaxone. Therefore, looking for an alternative drug is always required. Because B. megaterium T04 that was isolated in Vietnam, being a tropical country that will give many useful products. Therefore, the studies of cultivation conditions and potency and efficacy evaluation on antimicrobial activities of $B$. megaterium T04 were necessary.

\section{MATERIALS AND METHODS}

\section{Sample preparation}

Bacillus megaterium T04 isolated in Rach Lang stream in Vietnam was deposited in DNA Data Bank of Japan (DDBJ) with accession number LC052666. After incubation, the $B$. megaterium T04 cultures were centrifuged at $10.000 \mathrm{rpm}$ for $15 \mathrm{~min}$ at $4^{\circ} \mathrm{C}$. The collected cell free supernatant (CFS) was used for antimicrobial activity tests and starch hydrolysis ability test.

LB medium was used as a nutrient supplier for pathogen growth. LB agar plates with $2 \%$ agar were used in antimicrobial tests. Ceftriaxone was used to compare the activity to Bacillus megaterium T04 cultures. The purpose of this step was to determine potency antimicrobial activity of Bacillus megaterium T04 cultures.

\section{Test microorganisms and cultivation conditions}

The test microorganisms in this study included in Candida albicans (ATCC 10231) (yeast), the Gram-negative pathogens Salmonella typhi (ATCC 19430) and Pseudomonas aeruginosa (ATCC 27853), the Gram-positive pathogens Staphylococcus sciuri (ATCC 29061) and Micrococcus luteus (ATCC 10240). Each of these microorganisms was inoculated into LB broth at $37^{\circ} \mathrm{C}$ for 24 hours. The microorganism density of each culture was checked by measuring optical density at $600 \mathrm{~nm}$ in wavelength. In order to make uniform cultures of test pathogens, the $\mathrm{OD}_{600}$ of these cultures was adjusted to reach 0.2. All these pathogenic cultures were used as indicators for antimicrobial activity test. In order to study the effects of temperature and incubation time on Bacillus megaterium T04 biological activities, Bacillus megaterium T04 was incubated at different temperatures $\left(25,37,45^{\circ} \mathrm{C}\right)$ in different periods of time $(24,48,72$ hours $)$.

The 24-hour culture of Bacillus megaterium T04 was cultivated in $\mathrm{LB}$ medium at $37^{\circ} \mathrm{C}$ overnight to reach $\mathrm{OD}_{600}=$ 1.350. Then, $0.5 \mathrm{~mL}$ of this pre-culture was transferred into each medium with specific conditions of incubation. When the cultures obtaining a suitable bacterial amount $\left(57.3 \times 10^{8} \mathrm{cfu} / \mathrm{mL}\right)$, the cultures were used for antimicrobial activity test.

\section{Agar well diffusion method}

The antimicrobial test was done by applying agar well diffusion method (Cleidson et al., 2007). $20 \mu \mathrm{L}$ of prepared pathogenic microorganism culture was spread uniformly onto LB agar plate by using a sterile glass spreader. Then, wells were made on these pathogens containing LB plates by using a sterile cork borer (6 $\mathrm{mm}$ in diameter).

Each well was fulfilled with $100 \mu \mathrm{L}$ cell free supernatant collected from cultures of Bacillus megaterium T04. The systems were incubated at room temperature (RT). The results were recorded by observation and measurement of inhibition zones around the wells.

\section{Potency and efficacy evaluation}

In order to evaluate the potency and efficacy of the antimicrobial activities of Bacillus megaterium T04, ceftriaxone was used to compare.

The cultures $\left(57.3 \times 10^{8} \mathrm{cfu} / \mathrm{mL}\right)$ prepared in antimicrobial testing part were used to evaluate the potency and efficacy in antimicrobial activity.

Different concentrations of ceftriaxone $(10 \mathrm{mg} / \mathrm{mL}, 1$ $\mathrm{mg} / \mathrm{mL}, 0.1 \mathrm{mg} / \mathrm{mL}, 0.01 \mathrm{mg} / \mathrm{mL}, 0.001 \mathrm{mg} / \mathrm{mL}, 0.0001 \mathrm{mg} / \mathrm{mL}$ ) were assayed their activity against $C$. albicans, $S$. typhi, $P$. aeruginosa, S. sciuri, and M. luteus. Based on the ceftriaxone activity curves and minimal inhibitory concentration (MIC) of ceftriaxone, the antimicrobial activity potency and efficacy could be determined. All the tests were triplicated.

\section{Statistical analysis}

All the results obtained in the study were subjected to statistical treatment using SPSS software version 16.0. General linear model followed by post-hoc test was used to compare means of growth inhibition zones made by Bacillus megaterium T04 under different conditions. The significance of differences between the diameters of inhibition zones was determined at $p=0.05$.

\section{RESULTS AND DISCUSSION}

\section{Effects of incubation temperature}

The results revealed that Bacillus megaterium T04 could produce inhibition zones against pathogens at conditions of cultivation at $37^{\circ} \mathrm{C}$ (in the tests against Staphylococcus sciuri and Micrococcus luteus) and at $25^{\circ} \mathrm{C}$ (in the test against Staphylococcus sciuri). However, the negative results only detected in 72-hour cultures in LB medium at $45^{\circ} \mathrm{C}$ (in the tests against Candida albicans, Salmonella typhi, Staphylococcus sciuri, and Microccocus luteus (Figure 1, Table 1).

By statistical analysis, there were significant effects of cultivation medium and incubation time on the antagonistic activities of this Bacillus megaterium T04 strain against all test pathogens used in this study. Also, the result showed that incubation temperature affected significantly on the antimicrobial activity of the Bacillus megaterium T04 strain against almost test pathogens, except the unchangeable activities against Staphylococcus sciuri when Bacillus megaterium T04 was cultured in different temperature (Figure 1). 
Table 1: Activities of Bacillus megaterium T04 against pathogens.

\begin{tabular}{|c|c|c|c|c|c|}
\hline \multirow{2}{*}{$\begin{array}{l}\text { Cultivation condition } \\
\left.\text { (medium } /{ }^{\circ} \mathrm{C} / \mathrm{hrs}\right)\end{array}$} & \multicolumn{5}{|c|}{ Diameter of inhibition zone (mean \pm SD, mm) against pathogens } \\
\hline & C. albicans & S. typhi & P. aeruginosa & S. sciuri & M. luteus \\
\hline $\mathrm{LB} / 25^{\circ} \mathrm{C} / 24$ & $3.3 \pm 0.6$ & $4.7 \pm 0.3$ & $4.3 \pm 0.6$ & $8.5 \pm 0.5$ & $18.7 \pm 0.6$ \\
\hline $\mathrm{LB} / 25^{\circ} \mathrm{C} / 48$ & $5.2 \pm 0.8$ & $4.7 \pm 0.8$ & $12.7 \pm 0.6$ & $9.3 \pm 0.6$ & $6.3 \pm 0.6$ \\
\hline $\mathrm{LB} / 25^{\circ} \mathrm{C} / 72$ & $4.7 \pm 0.6$ & $4.3 \pm 0.6$ & $15.7 \pm 0.6$ & ND & $4.3 \pm 0.6$ \\
\hline $\mathrm{LB} / 37^{\circ} \mathrm{C} / 24$ & $7.7 \pm 0.6$ & $9.3 \pm 0.6$ & $13.2 \pm 0.8$ & $10.3 \pm 0.3$ & $12.3 \pm 0.6$ \\
\hline $\mathrm{LB} / 37^{\circ} \mathrm{C} / 48$ & $13.5 \pm 0.5$ & $9.7 \pm 0.3$ & $14.7 \pm 0.3$ & $7.7 \pm 0.6$ & $14.2 \pm 0.3$ \\
\hline $\mathrm{LB} / 37^{\circ} \mathrm{C} / 72$ & $10.8 \pm 0.3$ & $10.2 \pm 0.3$ & $10.8 \pm 0.3$ & ND & ND \\
\hline $\mathrm{LB} / 45^{\circ} \mathrm{C} / 24$ & $7.5 \pm 0.5$ & $16.8 \pm 0.8$ & $19.7 \pm 0.6$ & $8.7 \pm 0.6$ & $9.3 \pm 0.6$ \\
\hline $\mathrm{LB} / 45^{\circ} \mathrm{C} / 48$ & $5.7 \pm 0.6$ & $6.7 \pm 0.6$ & $11.3 \pm 0.6$ & $7.8 \pm 0.8$ & $8.3 \pm 0.6$ \\
\hline $\mathrm{LB} / 45^{\circ} \mathrm{C} / 72$ & ND & ND & $4.7 \pm 0.6$ & ND & ND \\
\hline
\end{tabular}

ND: not detected

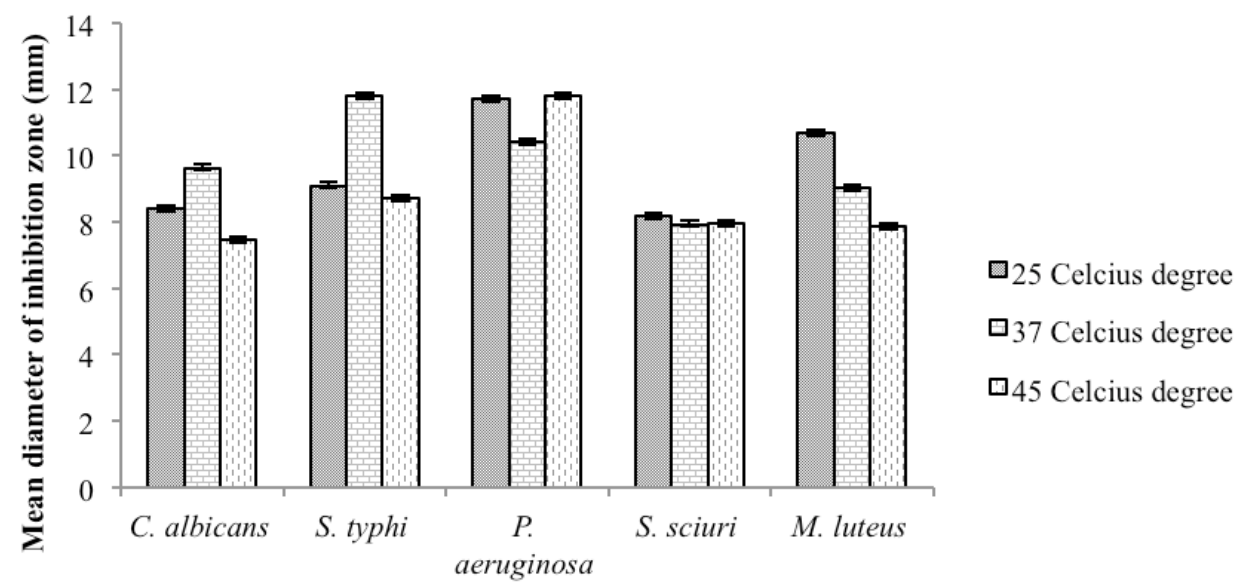

Test pathogens

Fig. 1: Effects of three cultivation temperatures on antimicrobial activities of Bacillus megaterium T04, done by post-hoc tests.

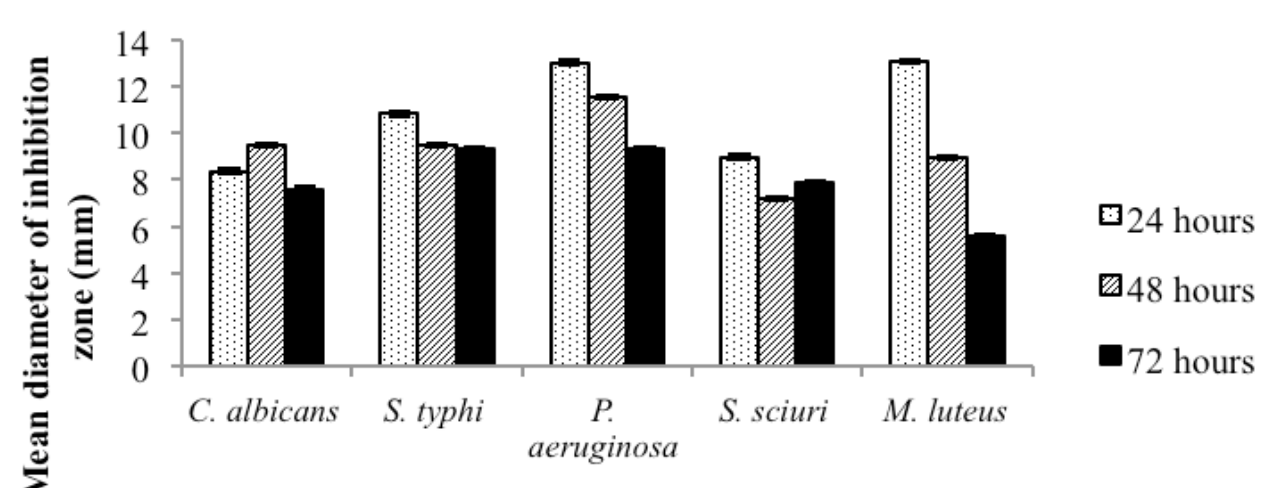

Test pathogens

Fig. 2: Effects of three cultivation time on activities of Bacillus megaterium T04, done by post-hoc.

The difference in activities with different incubation temperature suggested that there were different antimicrobial agents produced by Bacillus megaterium T04. Remarkably, Bacillus megaterium T04 that could act on Candida albicans, Staphylococcus sciuri and Microccocus luteus wasn't reported in studies on antimicrobial activities of Bacillus megaterium of Malanicheva et al. (2012).

\section{Effects of cultivation time}

The antimicrobial activities of the Bacillus megaterium T04 were checked in different conditions of cultivation time. The result of this test was shown in figure 2 , table 1 . The difference in activities in different incubation time suggested that there were different antimicrobial agents produced by Bacillus megaterium T04.

In the combination with the activities produced in different incubation of Bacillus megaterium T04, this strain could produce different antimicrobial agents in different stages.

Exploiting these properties of this strain, further studies will be done to develop a suitable Bacillus megaterium T04 formulation or its product for pharmaceutical science as well as life science. 
Table 2: Potency of antimicrobial activity of Bacillus megaterium T04 produced under different incubation conditions.

\begin{tabular}{|c|c|c|c|c|c|}
\hline \multirow[t]{2}{*}{$\begin{array}{l}\text { Cultivation condition } \\
\left.\text { (medium/ } /{ }^{\circ} \mathrm{C} / \mathrm{hrs}\right)\end{array}$} & \multicolumn{5}{|c|}{$\begin{array}{c}\text { Equivalent concentration of ceftriaxone (Mean } \pm \mathrm{SD}, \mu \mathrm{g} / \mathrm{mL}) \text { to antimicrobial activity of Bacillus megaterium } \mathrm{T04} \text { against test } \\
\text { pathogens }\end{array}$} \\
\hline & C. albicans & S. typhi & P. aeruginosa & S. sciuri & M. luteus \\
\hline $\mathrm{LB} / 25^{\circ} \mathrm{C} / 24$ & $3.1 \pm 0.5$ & $1.0 \pm 0.1$ & $0.4 \pm 0.1$ & $156.9 \pm 25.5$ & $64.4 \pm 7.4$ \\
\hline $\mathrm{LB} / 25^{\circ} \mathrm{C} / 48$ & $5.1 \pm 1.1$ & $1.0 \pm 0.2$ & $4.0 \pm 0.6$ & $206.6 \pm 40.8$ & $5.0 \pm 0.6$ \\
\hline $\mathrm{LB} / 25^{\circ} \mathrm{C} / 72$ & $4.5 \pm 0.7$ & $0.9 \pm 0.2$ & $9.3 \pm 1.4$ & ND & $3.3 \pm 0.4$ \\
\hline $\mathrm{LB} / 37^{\circ} \mathrm{C} / 24$ & $9.9 \pm 1.4$ & $3.9 \pm 0.7$ & $4.7 \pm 1.0$ & $283.7 \pm 26.0$ & $17.3 \pm 2.1$ \\
\hline $\mathrm{LB} / 37^{\circ} \mathrm{C} / 48$ & $46.5 \pm 6.2$ & $4.2 \pm 0.4$ & $7.0 \pm 0.6$ & $119.8 \pm 21.2$ & $25.2 \pm 1.5$ \\
\hline $\mathrm{LB} / 37^{\circ} \mathrm{C} / 72$ & $22.8 \pm 1.7$ & $4.9 \pm 0.4$ & $2.4 \pm 0.2$ & ND & ND \\
\hline $\mathrm{LB} / 45^{\circ} \mathrm{C} / 24$ & $9.5 \pm 1.3$ & $35.5 \pm 7.7$ & $28.4 \pm 4.4$ & $166.1 \pm 29.4$ & $9.3 \pm 1.1$ \\
\hline $\mathrm{LB} / 45^{\circ} \mathrm{C} / 48$ & $5.8 \pm 0.8$ & $1.8 \pm 0.3$ & $2.8 \pm 0.5$ & $127.6 \pm 30.3$ & $7.5 \pm 0.9$ \\
\hline $\mathrm{LB} / 45^{\circ} \mathrm{C} / 72$ & ND & ND & $0.4 \pm 0.1$ & ND & ND \\
\hline
\end{tabular}

ND: Not detected

\section{Potency of antimicrobial activity of Bacillus megaterium T04 cultures in comparison with ceftriaxone}

In order to study the antimicrobial activity potency of Bacillus megaterium T04 to, ceftriaxone was used as reference for comparison to the activity of the Bacillus megaterium T04 cultures. The equivalent concentration of ceftriaxone to the antimicrobial activity of Bacillus megaterium T04 was shown in table 2. According to the activity of ceftriaxone on each pathogen, the detected antimicrobial activity potency of Bacillus megaterium T04 against $C$. albicans was minimum at $3.1 \pm 0.5 \mu \mathrm{g} / \mathrm{mL}$ and maximum at $46.5 \pm 6.2 \mu \mathrm{g} / \mathrm{mL}$ of ceftriaxone. The detected antimicrobial activity potency of Bacillus megaterium T04 against Salmonella typhi ranged from $0.9 \pm 0.2$ to $35.5 \pm 7.7 \mu \mathrm{g} / \mathrm{mL}$ of ceftriaxone. In the test against Pseudomonas aeruginosa, the detected antimicrobial activity potency of the Bacillus megaterium T04 strain was equivalent to ceftriaxone activity at the concentration from $0.4 \pm 0.1 \mu \mathrm{g} / \mathrm{mL}$ to $28.4 \pm 4.4 \mu \mathrm{g} / \mathrm{mL}$. For Staphylococcus sciuri, the detected antimicrobial activity potency was from $119.8 \pm 21.2 \mu \mathrm{g} / \mathrm{mL}$ to $283.7 \pm 26.0 \mu \mathrm{g} / \mathrm{mL}$ of ceftriaxone. Similarly, the detected antimicrobial activity of Bacillus megaterium T04 against Micrococcus luteus was evaluated to range from $3.3 \pm 0.4 \mu \mathrm{g} / \mathrm{mL}$ to $64.4 \pm 7.4 \mu \mathrm{g} / \mathrm{mL}$ of ceftriaxone. To understand the efficacy of Bacillus megaterium T04 against the pathogens, the antimicrobial activity capacity was compared with the in-vitro MICs of ceftriaxone on each pathogen. As a result, the Bacillus megaterium T04 could give the strong inhibition effects on all test pathogens ( $C$. albicans, S. typhi, P. aeruginosa, S. sciuri, and $M$. luteus) since they could produce antimicrobials at higher concentrations than the in-vitro MICs of ceftriaxone (Table 2, table 3).

Table 3: In vitro minimal inhibitory concentrations (MICs) of ceftriaxone against some pathogens.

\begin{tabular}{cc}
\hline Pathogens & $\begin{array}{c}\text { In vitro MICs of ceftriaxone against test } \\
\text { pathogens }(\boldsymbol{\mu g} / \mathbf{m L})\end{array}$ \\
\hline C. albicans & 52.8 \\
S. typhi & 15.1 \\
P. aeruginosa & 5.8 \\
S. sciuri & 935.6 \\
M. luteus & 24.29 \\
\hline
\end{tabular}

Bacillus megaterium T04 presented broad spectrum of antimicrobial activity since it showed the potency and efficacy to against gram-negative (Salmonella typhi, Pseudomonas aeruginosa), gram-positive pathogens (Staphylococcus sciuri, Micrococcus luteus), and the yeast pathogen (Candida albicans). This is a positive sign for the application of this Bacillus megaterium T04 strain isolated in Vietnam conditions to pharmaceutical field. Hopefully, the antimicrobial agents of Bacillus megaterium T04 will be used in alternative for patients being hypersensitivity to beta-lactam drugs.

Culture conditions, including culture medium, incubation temperature, incubation period, and also the interactions of these factors had considerable effects on the exhibition of antimicrobial activity of the Bacillus megaterium T04.

\section{CONCLUSION}

Bacillus megaterium T04 was preliminary detected to have a broad spectrum of antimicrobial activity against fungi (Candida albicans), Gram-positive bacteria (Staphylococcus sciuri, Micrococcus luteus), and Gram-negative bacteria (Salmonella typhi, Pseudomonas aeruginosa). The antimicrobial agents produced in Bacillus megaterium T04 could be stronger than ceftriaxone, one of third-generation of cephalosporin. Therefore, Bacillus megaterium T04 would be a potential source for antimicrobial agents.

\section{REFERENCES}

Abriouel H, Franz CMAP, Omar NB and Gálvez A. Diversity and applications of Bacillus bacteriocins. FEMS Microbiol Rev, 2011; 35: 201-232.

Brusilow WS and Nelson DL. Improved purification and some properties of megacin $\mathrm{Cx}, \mathrm{a}$ bacteriocin produced by Bacillus megaterium. J Biol Chem, 1981; 256: 159-164.

Donoghue HD. Properties and comparative starch-gel electrophoresis of megacins from several Bacillus megaterium strains. $J$ Gen Microbiol, 1972; 72: 473-483.

Holland IB and Roberts CF. Some properties of a new bacteriocin formed by Bacillus megaterium. J Gen Microbial, 1964; 35 : 271-285.

Khalil R, Djadouni F, Elbahloul Y and Omar S. The influence of cultural and physical conditions on the antimicrobial activity of bacteriocin produced by a newly isolated Bacillus megaterium 22 strain. Afr J Food Sci, 2009a; 3: 011-022.

Khalil R, Elbahloul Y, Djadouni F and Omar S. Isolation and partial characterization of a bacteriocin produced by a newly 
isolated Bacillus megaterium 19 strains. Pakistan J Nutr, 2009b;8: 242250.

Malanicheva IA, Kozlov DG, Sumarukova IG, Efremenkova OV, Zenkova VA, Katrukha GS, Reznikova, Tarasova OD, Sineokii SP, EI' Registan GI. Antimicrobial activity of Bacillus megaterium strains. Microbiology, 2012; 31(2): 178-185.

Maulin PS. Bioremedial Application of Bacillus megaterium PMS82 in Microbial Degradation of Acid Orange Dye. International Journal of Environmental Bioremediation \& Biodegradation, 2014; 2(3): 93-99.

Morita M, Tomita K, Ishizawa M, Takagi K, Kawamura F, Takahashi H, Morino T. Cloning of oxetanocin A biosynthetic and resistance genes that reside on a plasmid of Bacillus megaterium strain NK84-0128. Biosci Biotechnol Biochem, 1999; 63: 563-566.

Rodriguez-Contreras A, Koller M, Miranda-de Sousa Dias M, Calafell-Monfort M, Braunegg $G$ and Marques-Calvo MS. High production of poly (3-hydroxybutyrate) from a wild Bacillus megaterium Bolivian strain. J Appl Microbiol, 2013; 114(5): 1378-1387.

Saxena A, Zhang RW and Bollag JM. Microorganism: capable of metabolizing the herbicide metolachlor. Appl Enviro Microbiol, 1987; 53: $390-396$

Selvanayagam $M$ and Vijaya J. Degradation of persistent insecticides by aquatic bacteria as sole source of carbon. $J$ Enviro Biol, 1989; 10: 399-407.

Shimada N, Hasegawa S, Harada T, Tomisawa T, Fujii A, Takita T. Oxetanocin, a novel nucleoside from bacteria. J Antibiot (Tokyo) 1986; 39:1623-1625.
Shiota H, Nitta K, Naito T, Mimura Y, Maruyama T. Clinical evaluation of carbocyclic oxetanocin $\mathrm{G}$ eyedrops in the treatment of herpes simplex corneal ulcers. Br J Ophthalmol, 1996; 80: 413-415

Tseng CK, Marquez VE, Milne GW, Wysocki RJ, Mitsuya H, Shirasaki T, Driscoll JS. A ring-enlarged oxetanocin A analogue as an inhibitor of HIV infectivity. J Med Chem, 1991; 34: 343-349.

Vary PS, Biedendieck R, Fuerch T, Meinhardt F, Rohde M, Deckwer WD, Jahn D. Bacillus megaterium-from simple soil bacterium to industrial protein production host. Appl Microbiol Biotechnol, 2007; 76 (5): 957-967.

Vary PS. Development of genetic engineering in Bacillus megaterium: an example of the versatility and potential of industrially important bacilli. In Biology of Bacilli: Applications to Industry, 1992; 251-310.

Vary PS. 1994. Prime time for Bacillus megaterium. Microbiology, 140:1001-1013.

\section{How to cite this article:}

Tu HK Nguyen, Le B Thu. Evaluation of antimicrobial activities of Bacillus megaterium with a third-generation cephalosporin (ceftriaxone). J App Pharm Sci, 2015; 5 (09): 016-020. 